\title{
Adult Congenital Heart Disease - Need for Specialized Attention and Transition of Care
}

\author{
Pradheep Krishnamohan* \\ Cardiothoracic surgeon, CARE Hospitals, India
}

Submission: December 21, 2016; Published: January 05, 2017

*Corresponding author: Pradheep Krishnamohan, Consultant Cardiothoracic surgeon, CARE Hospitals, Hitch City, Old Mumbai Highway, Hyderabad 32, India, Ph: +919894255675; Email: Dr.pradheep.mohan@carehospitals.com

\section{Introduction}

Adult Congenital Heart Diseases (ACHD) includes adults who have congenital heart disease present from birth or acquire later in life due to a genetic predisposition present at birth. The true incidence of adults with congenital heart disease (ACHD) is unknown. With improved outcomes in neonatal and infant cardiac surgery, proportion of patients surviving to adulthood has increased.

As more neonates and children are treated for congenital heart diseases, this subset of patient population has increased in recent years. With increased survival, children with congenital heart diseases who grow up to become adults often require repetitive hospital visits and admissions and also multiple procedures over the course of a lifetime. Most recent estimate puts the number of adults with Congenital Heart Disease close to a million in the United States alone. Care of these patients becomes important as early diagnosis and improved treatment outcomes will prolong the survival of this patient population and also enable them to lead meaningful and productive lives.

Patients with congenital heart disease who have been followed by a congenital cardiologist during their childhood, when they become adults, the transition of care is often not seamless and without a hiccup.

\section{Modes of Presentation}

Adult Congenital Heart Diseases patients can have varied presentation. Some patients with simple congenital lesions often survive to near normal lifespan. They can have undiagnosed congenital heart lesion from birth (Atrial septal defects, coronary artery anomalies, and Ebstein's anomaly) that comes to light later in life as adults. They can present for surgery as adults for the first time:

a. For the primary lesion

b. Secondarily associated complications from uncorrected defects (atrial fibrillation, tricuspid regurgitation from dilated $\mathrm{RV}$ in left to right shunts)

They can also present with acquired coronary artery disease, valvular heart disease etc. Sometimes, presentation for coronary artery disease or degenerative aortic stenosis might bring to light a previously undiagnosed ASD or coronary artery anomaly etc. Alternatively, they can have diagnosed and treated congenital heart disease in childhood (tetralogy of Fallot, AV canal defect) and present later in adulthood for one of the reasons - residual defect or recurrence of atrial or ventricular septal defect or other congenital lesion, one of the consequence of treated congenital lesions (as in pulmonary regurgitation after previous tetralogy repair), unrelated acquired condition (coronary artery disease, degenerative mitral regurgitation) etc. They can present in various combinations of the above factors.

Patients with congenitally abnormal aortic valves are a different subgroup of adult congenital patients in that they are born with an anatomically abnormal aortic valve that is often functioning normally at birth but genetically predisposed to earlier degeneration than normal valves. While some present in childhood with aortic stenosis and often have history of repeated balloon valvuloplasty, larger proportion of patients develop symptoms later in life starting from 3rd or 4th decade of life. Patients with genetic syndromes like Marfan's, Turner's, and Down's syndrome etc. are more heterogeneous because of the spectrum of cardiac anomalies they can present with and the varying ages at the time of presentation.

\section{Issues with managing Adult Congenital Patients}

One of the significant issues that confront surgery for ACHD is the lack of clear understanding of the anatomy and physiology of this patient subset that are often treated by adult cardiologist and the health team who are not aware of the complexity of the adult with a congenitally abnormal heart. Also, these patients 
who were being followed up in pediatric centres while they were kids get lost during transition of care to adults. There are not many specialized adult congenital cardiac centres and even less, education about the need for specialized surveillance for these patients and the family support, who often receive no follow up care at all till they become symptomatic.

Thus lack of awareness among the patient and family members about the existing ailment and the likely need for lifelong follow-up, non availability of specialized care centres to deal with such patients even when there is familial awareness and often loss of follow up due to various social, economic and family reasons - all of the above put the adult congenital heart disease patient under risk for substantial jeopardy. Also the adult physicians and cardiologists who are adept at seeing the regular adult patient with various acquired heart disease and conditions may not be adequately educated about the complexity of an adult patient with congenitally abnormal hearts.

Adult Congenital patients who have been treated for congenital heart disease in childhood often will need repeated procedures during the course of their lifetime ranging from pacemaker change to valve and conduit replacements to even heart and/or lung transplantation.

\section{Where are we in 2016 ?}

Centres specializing in adults with congenitally malformed hearts have existed in Europe for several years now. The number of adult congenital specialized centres in the United States has increased very recently and is still not standardized with respect to infrastructure and availability of specialists and multidisciplinary collaboration.

Information about the adult congenital heart disease patients are not plenty. Most of the existing congenital heart disease registries, nationally and internationally, have failed to capture information once the patient reach adulthood that are then captured in the regular clinical outcomes registries. There is a dearth of knowledge when we looked into literature for information about these patients. The longitudinality of altered natural history in these patients who undergo multiple procedures and interventions is not captured in the current registries which are good at capturing information at any one particular point in time. Thus, studies on natural history of these adult congenital patients are lacking.

While there is increasing awareness among specialists in Europe and North America about the existence of this subset of Adult Congenital patients and the need for specialized care, the situation is far from good in developing and underdeveloped countries in Asia and Africa where there is a large burden of congenital heart disease patients. Lack of basic medical facilities and poor infrastructure, diagnosis is often missed in these patients in childhood, who become adults and present late in the natural history. There is a larger proportion of untreated adult congenital patients presenting late in the natural history of disease in Asia and Africa (compared to Europe and North America) who will need specialized care parallel to the subset of treated adult congenital patients who also present for follow up care and repeat procedures [1-5].

It is imperative that physicians recognize the existence of these patients and are adequately educated to identify and manage and appropriately refer to specialists when needed in this part of the world. Further, national and international governmental and non governmental agencies should step up efforts to coordinate with existing health infrastructure of the local region to plan and expand the scope of medical and ancillary support services to this group of patients who will be a sizeable population driving the local economy in that region to lead a more productive and healthier life.

\section{References}

1. O'Leary JM, Siddiqi OK, de Ferranti S, Landzberg MJ, Opotowsky AR (2013) The Changing Demographics of Congenital Heart Disease Hospitalizations in the United States,1998 Through 2010. JAMA 309(10): 984-986.

2. Dearani JA, Connolly HM, Martinez R, Fontanet H, Webb GD (2007) Caring for adults with congenital cardiac disease: successes and challenges for 2007 and beyond. Cardiol Young 17(2): 87-96.

3. Hoffman JI, Kaplan S (2002) The incidence of congenital heart disease. J Am Coll Cardiol 39(12): 1890-1900.

4. Gary D Webb, Roberta G Williams (2001) Care of the adult with congenital heart disease: $32^{\text {nd }}$ Bethesda Conference. J Am Coll Cardiol 37(5): 1161-1189.

5. Somerville J (1997) Management of adults with congenital heart disease: an increasing problem. Annu Rev Med 48: 283-293.

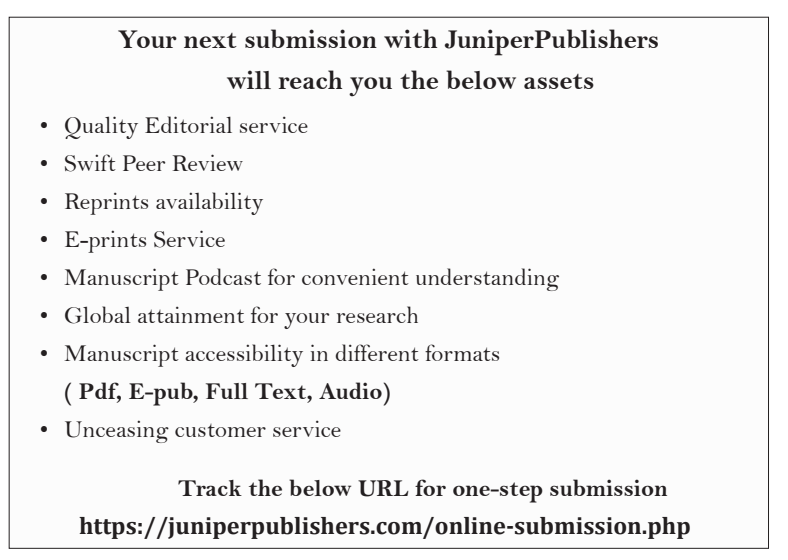

